\title{
Health Care Interventions Delivered Over the Internet: How Systematic was the Review?
}

Evan Mayo-Wilson

\section{Corresponding Author:}

Evan Mayo-Wilson

Centre for Evidence-Based Intervention, Department of Social Policy and Social Work

Barnett House

32 Wellington Square

Oxford OX1 2ER

United Kingdom

Phone: +44 (0) 1865280339

Fax: +44 (0) 1865270324

Email: Evan.Mayo-Wilson@socres.ox.ac.uk

\section{Related Articles:}

Comment on:Griffiths F, Lindenmeyer A, Powell J, Lowe P, Thorogood M. Why Are Health Care Interventions Delivered Over the Internet? A Systematic Review of the Published Literature. J Med Internet Res. 2006 Jun 23;7(2) p. e10 http://www.jmir.org/2006/2/e10/

Comment in:Griffiths F. Health Care Interventions Delivered Over the Internet: How Systematic was the Review? - Author's Reply. J Med Internet Res. 2006 Jun 30;8(2) p. e12 http://www.jmir.org/2006/2/e12/

(J Med Internet Res 2006;8(2):e11) doi: 10.2196/jmir.8.2.e11

I found the title and description of the recent review by Griffiths et al. [1] misleading. The authors describe their paper as "a systematic review". However, the article fails to cite several published (and indexed) trials of internet-delivered therapy (e.g. [2]). The search strategy and inclusion criteria were neither transparent nor replicable. The authors note that they did not "set out to identify every published eHealth intervention paper" yet give no reason to believe that the sample obtained is representative of the population of studies being reviewed.

\section{References}

1. Griffiths F, Lindenmeyer A, Powell J, Lowe P, Thorogood M. Why Are Health Care Interventions Delivered Over the Internet? A Systematic Review of the Published Literature. J Med Internet Res 2006 Jun 23;7(2):e10 [FREE Full text] [doi: 10.2196/jmir.8.2.e10]

2. Klein B, Richards JC. A Brief Internet-based Treatment for Panic Disorder. Behav Cog Psychother 2001 Mar 06;29(1):113-117. [doi: 10.1017/S1352465801001138]

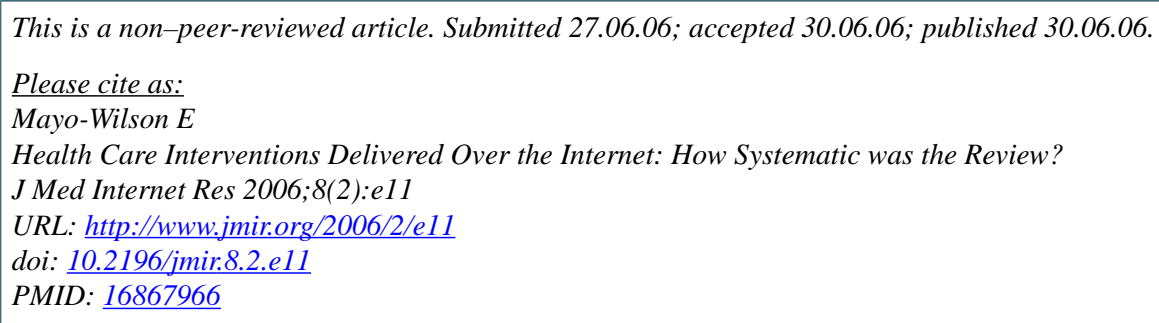

(C) Evan Mayo-Wilson. Originally published in the Journal of Medical Internet Research (http://www.jmir.org), 30.6.2005. Except where otherwise noted, articles published in the Journal of Medical Internet Research are distributed under the terms of the Creative Commons Attribution License (http://www.creativecommons.org/licenses/by/2.0/), which permits unrestricted use, distribution, and reproduction in any medium, provided the original work is properly cited, including full bibliographic details and the URL (see "please cite as" above), and this statement is included. 